\title{
Microwave-Assisted Preparation of Organo-Lead Halide Perovskite Single Crystals
}

\author{
Jan Jancik, Anna Jancik Prochazkova," Markus Clark Scharber, Alexander Kovalenko, Jiří Másilko, \\ Niyazi Serdar Sariciftci, Martin Weiter, and Jozef Krajcovic**
}

Cite This: Cryst. Growth Des. 2020, 20, 1388-1393

Read Online

\section{ACCESS I}

Џll Metrics \& More

Article Recommendations

Supporting Information

ABSTRACT: The efficiency of organo-lead halide perovskite-based optoelectronic devices Perovskite precursor Microwave Single is dramatically lower for amorphous materials compared to highly crystalline ones. solution radiation crystal Therefore, it is challenging to optimize and scale up the production of large-sized single crystals of perovskite materials. Here, we describe a novel and original approach to preparing lead halide perovskite single crystals by applying microwave radiation during the crystallization. The microwave radiation primarily causes precise heating control in the whole volume and avoids temperature fluctuations. Moreover, this facile microwave-assisted method of preparation is highly reproducible and fully automated, it and can be applied for various different perovskite structures. In addition, this cost-effective method is expected to $\rightleftharpoons$

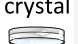
be easily scalable because of its versatility and low energy consumption. The crystallization process has low heat losses; therefore, only a low microwave reactor power of $8-15 \mathrm{~W}$ during the temperature changes and of less than $1 \mathrm{~W}$ during the temperature holding is needed.

$\mathrm{O}$ rgano-lead halide perovskites of the general formula $\mathrm{APbX}_{3}$, where $\mathrm{A}$ stands for a monovalent organic cation (for example, the commonly used methylammonium = MA, or formamidinium $=\mathrm{FA}$ ) and $\mathrm{X}$ represents a halide anion or halide anions mixtures $\left(\mathrm{Cl}^{-}, \mathrm{Br}^{-}, \mathrm{I}^{-}\right),{ }^{1}$ are promising materials for the development of photovoltaic cells, ${ }^{1-3}$ light emitting diodes, ${ }^{4,5}$ lasers, ${ }^{6-8}$ ultraviolet-to-infrared photodetectors ${ }^{9-11}$ and X-ray and $\gamma$-ray detectors. ${ }^{12,13}$ The success comes from their unique properties such as a suitable bandgap, high absorption coefficient, tunable optical properties, long and balanced electron-hole diffusion lengths, and low exciton binding energy. ${ }^{14-17}$

Perovskites can easily be deposited from their precursor solutions into a thin film by solution-based processes. ${ }^{18-24}$ These processes are low-cost, convenient, and efficient. Nevertheless, the prepared films possess defects that cause nonradiative recombination, current-voltage hysteresis, and rapid degradation due to the low stability of the resulting devices. $1,16,17,25-28$ The limitations can be reduced through preparation of single crystals, which possess low trap densities, higher crystallinity, and fewer ionic defects and grain boundaries, and thus the efficiency of the resulting functional devices can increase dramatically. ${ }^{1,17}$ There are several approaches for how a single perovskite crystal can be grown: slow evaporation, ${ }^{29}$ inversion temperature crystallization (ITC), ${ }^{30}$ modified inversion temperature crystallization, ${ }^{31}$ antisolvent vapor assisted, ${ }^{32}$ top seeded solution crystal growth, ${ }^{33}$ bottom seeded solution crystal growth, ${ }^{34}$ the temperature lowering method, ${ }^{35}$ and the Bridgman growth method. ${ }^{36}$ The ITC method uses the deterioration of the precursors' solubility with increasing temperature. Crystal growth is provided at higher temperatures, and temperature graduation must be regulated very precisely. ${ }^{30}$ In general, the crystal growth is dependent on the speed at which temperature rises, the number of heating steps, the heating medium used, and many other external factors, and therefore, the crystallization cannot be completely controlled and monitored. The effects of external factors mostly lead to a production of fusion crystals, crystal clusters, or crystal fields completely inappropriate for application in electronic devices. ${ }^{15}$

Microwave-assisted synthesis has been successfully applied in the preparation of various types of inorganic ${ }^{37}$ and organic compounds, ${ }^{38}$ complexes and nanoparticles ${ }^{37}$ including technological processes. ${ }^{39}$ The major advantage of microwave irradiation consists in the conversion of electric energy into kinetic energy of particles by dielectric heating. Kinetic energy is ultimately converted into heat, and therefore, homogeneous and fast heating of the reaction mixture is very precisely controllable, and this leads to higher reaction yields, improved reproducibility, and very easy upscaling for applications in industrial fields. ${ }^{39}$

Here, we have developed efficient and fully reproducible microwave-assisted synthesis of organo-lead halide perovskite single crystals as a means to eliminate all of the abovementioned problems. Our research provides a novel and

Received: December 15, 2019

Revised: January 31, 2020

Published: February 10, 2020 

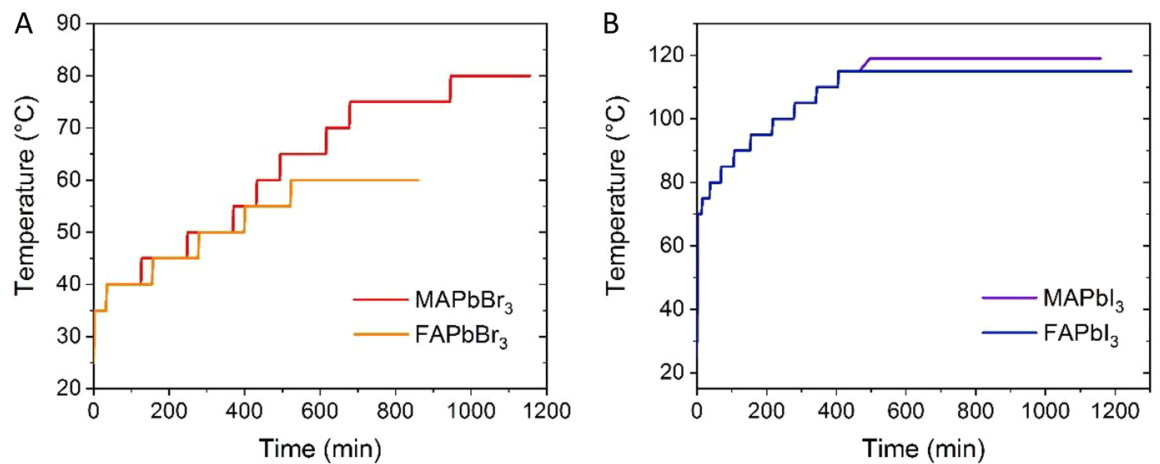

Figure 1. Temperature profiles for preparation of bromide-based (A) and iodide-based (B) perovskite single crystals.
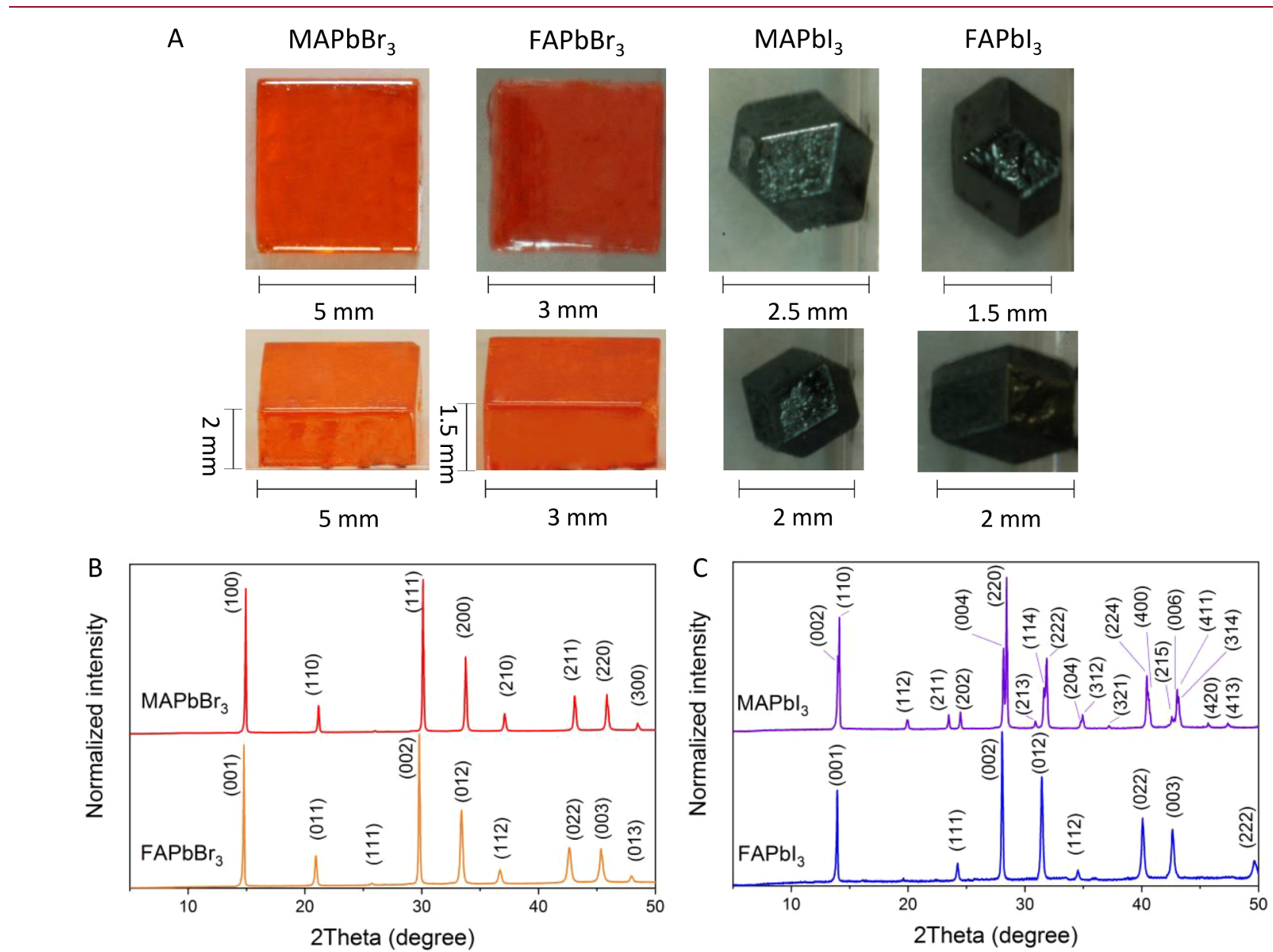

Figure 2. Photos of discussed perovskite single crystals (A) and powder XRD spectra of bromide-based (B) and iodide-based (C) perovskite single crystals.

original approach for growth of large-sized perovskite crystals with a highly organized crystal lattice by applying microwave radiation. We have found that lead-halide perovskite crystallization is not as time-consuming and energy-intensive as conventional methods due to effective heating. Moreover, the production of only one mostly bigger single crystal was followed. This new approach is highly efficient, reproducible, and easily upscalable because of the precise heating control.

As precursors $\mathrm{MABr}$ (methylamonium bromide, 98\%, Sigma-Aldrich), MAI (methylamonium iodide, 98\%, Dyesol), $\mathrm{FABr}$ (formamidinium bromide, > 98\%, Ossila), FAI (formamidinium iodide, > 98\%, Ossila), $\mathrm{PbBr}_{2}$ (lead(II) bromide, 99.999\%, Sigma-Aldrich), and $\mathrm{PbI}_{2}$ (lead(II) iodide, perovskite grade, Sigma-Aldrich) were used without any further purification. The solvents used were DMF $(N, N-$ dimethylformamide, anhydrous synthesis grade, Fisher Scientific) and GBL ( $\gamma$-butyrolactone, reagent plus >99\%, SigmaAldrich).

Organo-lead halide perovskite single crystals of $\mathrm{MAPbBr}_{3}$, $\mathrm{MAPbI}_{3}, \mathrm{FAPbBr}_{3}$, and $\mathrm{FAPbI}_{3}$ were prepared by the ITC method described in our previous work ${ }^{40-42}$ with a modification. Perovskite precursor solutions were prepared from a $1 \mathrm{M}$ solution of $N, N$-dimethlyformamide (DMF) for $\mathrm{MAPbBr}_{3}$ and $\gamma$-butyrolactone (GBL) in the case of $\mathrm{MAPbI}_{3}$ and $\mathrm{FAPbI}_{3}$, whereas the lead halides and corresponding organohalides were kept in a molar ratio of $1: 1$. In order to 

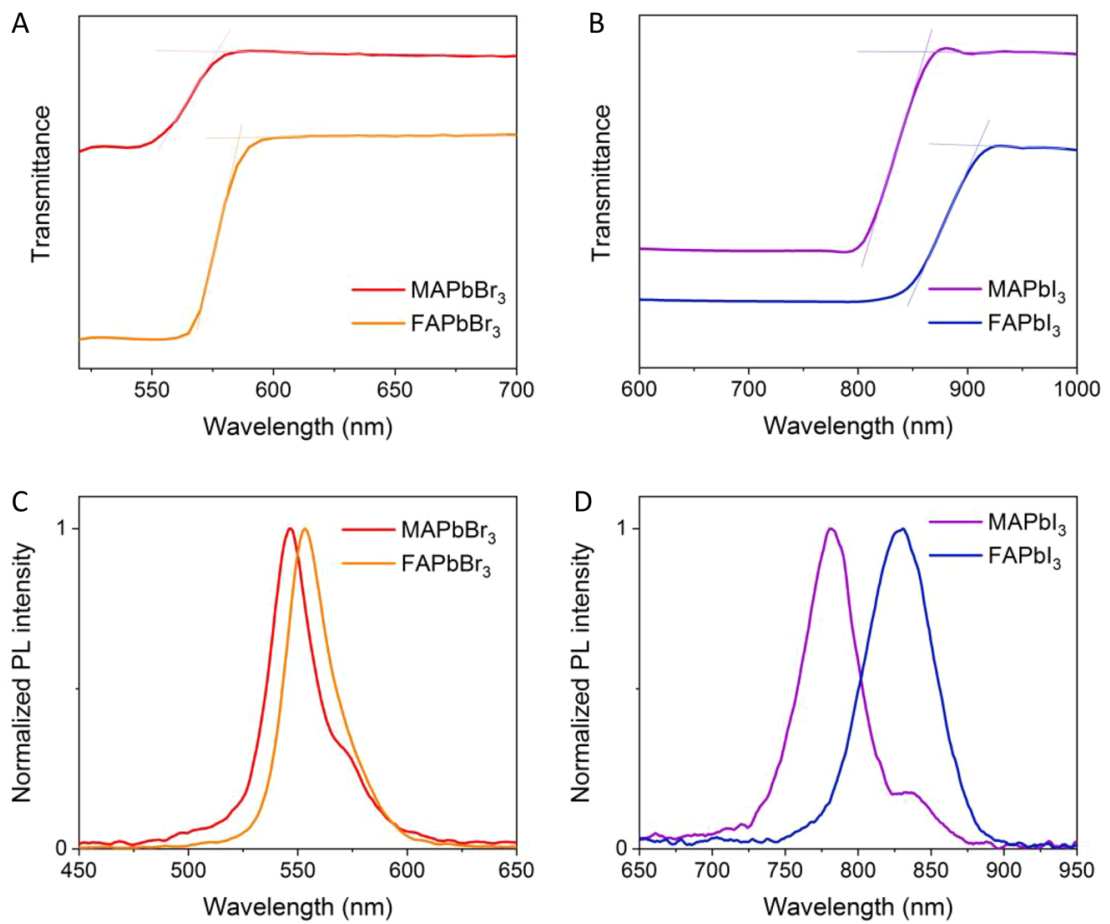

Figure 3. Optical characterization of perovskite single crystals, UV-vis spectra of bromide-based (A) and iodide-based (B) perovskites and PL spectra of bromide-based (C) and iodide-based (D) perovskite; the excitation wavelength was $405 \mathrm{~nm}$.

prepare a homogeneous $\mathrm{MAPbI}_{3}$ perovskite precursor solution, it was necessary to heat the suspension to $60{ }^{\circ} \mathrm{C}$ and to sonicate it. The $\mathrm{FAPbBr}_{3}$ perovskite precursor solution was prepared from a $1 \mathrm{M}$ solution of $\mathrm{PbBr}_{2}$ and $\mathrm{FABr}$ dissolved in a mixture of solvents DMF and GBL in a molar ratio of 1:1. In all cases, the precursor solution was filtrated over a PTFE syringe filter $(0.45 \mu \mathrm{m})$, and the filtrate was placed into a microwave reactor. For the preparation of all the crystals, the total volume of the resulting perovskite precursor solution was $2 \mathrm{~mL}$, and the preparation of the precursor solution was performed under ambient conditions. The crystallization was performed in a microwave reactor (Anton Paar Monowave $300)$ in a G10 glass reactor with a Ruby thermometer in an immersion tube. The temperature program was set according to our previous experiments, ${ }^{40-42}$ and this is shown in detail in Figure 1A,B for bromide-based and iodide-based perovskite crystals, respectively. The temperature profiles for $\mathrm{MAPbBr}_{3}$, $\mathrm{MAPbI}_{3}, \mathrm{FAPbBr}_{3}$, and $\mathrm{FAPbI}_{3}$ were set in intervals from 35 to $80{ }^{\circ} \mathrm{C}$, from 70 to $119^{\circ} \mathrm{C}$, from 35 to $60{ }^{\circ} \mathrm{C}$, and from 70 to $115{ }^{\circ} \mathrm{C}$, respectively. The optimized crystallization programs were saved in the instrument's memory, and high reproducibility was observed.

During the optimization experiments, we observed that faster temperature increases led to polycrystalline material formation. For example, with regard to the preparation of bromide-based perovskite crystals, when the temperature was being increased in $10{ }^{\circ} \mathrm{C}$ steps with $30-60$ min intervals, the polycrystals consisting of tiny (less than $0.5 \mathrm{~mm}$ ) blended crystals were formed. On the other hand, when the temperature was being increased gradually with more steps $\left(5{ }^{\circ} \mathrm{C}\right.$ steps $)$ and at longer intervals $(60-120 \mathrm{~min})$, as shown in Figure 1A, single crystals were grown in all cases, which is in the line with the previous work. ${ }^{40-42}$ Furthermore, the longer the highest temperature value was set, the larger the resulting single crystals were, which has also been described previously. ${ }^{40-42}$ For instance, when a temperature over 75 ${ }^{\circ} \mathrm{C}$ was set for $\mathrm{MAPbBr}_{3}$ perovskite for $1 \mathrm{~h}$, the single crystal obtained was only $1 \mathrm{~mm}$ in size; nevertheless, when a temperature over $75{ }^{\circ} \mathrm{C}$ was set almost for $8 \mathrm{~h}$, then the resulting single crystal was $5 \mathrm{~mm}$ in size as shown in Figure 2A. Finally, we have optimized programs for each perovskite crystal type by changing the speed of heating and the time at the set temperature according to Figure 1, and similar trends were observed in the preparation of iodide-based single crystals.

The photos of crystal samples prepared from $2 \mathrm{~mL}$ precursor solution by the above-mentioned methods with their dimensions are shown in Figure 2. As expected, the orange bromide-based perovskite single crystals were cubic. The microwave reactor's software limited the length of the crystallization program, and thus the maximal obtained size was $5 \pm 1$ and $3 \pm 0.5 \mathrm{~mm}$ for $\mathrm{MAPbBr}_{3}$ and $\mathrm{FAPbBr}_{3}$ crystals, respectively. With regard to the iodide-based perovskite crystals, the black "hexagonal based" single crystals were regular and $2.5 \pm 0.3$ or $1.5 \pm 0.3 \mathrm{~mm}$ in size in the case of $\mathrm{MAPbI}_{3}$ and $\mathrm{FAPbI}_{3}$ perovskites, respectively.

The mechanism of crystallization is considered to be the same as in the conventional ITC method. Used solvents (DMF and GBL) are suitable for microwave heating because of the presence of a dipole moment in the molecules, and thus, they can interact with the microwave irradiation which can be homogeneously absorbed through the whole volume of the sample, and as gained kinetic energy can be transferred into heat. ${ }^{39}$ Compared to conventional ITC methods, the microwave-assisted method for perovskite single crystals preparation is not influenced by many different parameters, such as temperature profile, pressure, external mechanical factors, etc. ${ }^{2}$ Microwave-assisted crystallization enhanced the reproducibility by means of precise temperature and environment monitoring. Simultaneously, the homogeneous heating of the sample was supposed to help to create one nucleation center. Finally, the 
crystallization was less time- and energy-consuming because of effective heating across the whole volume and because of the low $8-15 \mathrm{~W}$ power of the microwave reactor during the temperature changes and of less than $1 \mathrm{~W}$ during the temperature holding, the power profile is given in detail in Figure S1. This is a significantly lower energy when compared to a classic magnetic stirrer with a power of $800 \mathrm{~W}$ needed during the whole procedure.

In order to confirm the perovskite structure, we have performed a powder XRD analysis (see Figure 2B,C). Powder XRD measurements were performed on an Empyrean (PANalytical) diffractometer using $\mathrm{Cu} \mathrm{K} \alpha \quad\left(\begin{array}{ll}1.540598 & \AA\end{array}\right)$ radiation. The measurement parameters were as follows: tube current $30 \mathrm{~mA}$ and voltage $40 \mathrm{kV}$; scan axis gonio; step size $0.013^{\circ} 2 \theta$; time per step $96 \mathrm{~s}$. The results were evaluated using the software HighScore Plus. With regard to the $\mathrm{MAPbBr}_{3}$ perovskite structure, the cubic $P m \overline{3} m$ space group was confirmed with a unit cell parameter $a=5.9355 \AA$. The peaks positioned at $14.91^{\circ}, 21.19^{\circ}, 25.92^{\circ}, 30.16^{\circ}, 33.75^{\circ}$, $37.06^{\circ}, 43.13^{\circ}$, and $45.89^{\circ} 2 \theta$ correspond to the reflections (100), (110), (111), (200), (210), (211), (220), and (300), respectively. ${ }^{43}$ The $\mathrm{FAPbBr}_{3}$ perovskite structure was cubiclike as well with the space group $P m \overline{3} m$ and unit cell parameter $a=5.9993 \AA$. The found peaks at $14.84^{\circ}, 20.98^{\circ}, 25.78^{\circ}$, $29.73^{\circ}, 33.40^{\circ}, 36.71^{\circ}, 42.64^{\circ}, 45.39^{\circ}$, and $48.01^{\circ} 2 \theta$ correspond to the reflections (001), (011), (111), (002), (012), (112), (022), (003), and (013), respectively. ${ }^{44}$ The $\mathrm{MAPbI}_{3}$ perovskite crystal was in the tetragonal $I 4 / \mathrm{mcm}$ space group with unit cell parameters $a_{(001)}=12.6569 \AA ; b_{(110)}=$ $6.2741 \AA ; c_{(101)}=7.2708 \AA$. Peaks found at $13.98^{\circ}, 14.10^{\circ}$, $19.91^{\circ}, 23.46^{\circ}, 24.47^{\circ}, 28.15^{\circ}, 28.42^{\circ}, 30.89^{\circ}, 31.62^{\circ}, 31.83^{\circ}$, $34.78^{\circ}, 34.94^{\circ}, 37.19^{\circ}, 40.44^{\circ}, 40.63^{\circ}, 42.58^{\circ}, 42.80^{\circ}, 43.03^{\circ}$, $43.20^{\circ}, 45.69^{\circ}$, and $47.37^{\circ} 2 \theta$ correspond to the reflections (002), (110), (112), (211), (202), (004), (220), (213), (114), (222), (204), (312), (321), (224), (400), (215), (006), (411), (314), (420), and (413), respectively. ${ }^{45}$ The $\mathrm{FAPbI}_{3}$ perovskite crystal's phase was confirmed to be in an $\alpha$-phase whose space group is $P m \overline{3} m$ with unit cell parameter $a=6.3626 \AA$. Observed peaks at $13.99^{\circ}, 20.49^{\circ}, 24.22^{\circ}, 28.04^{\circ}, 31.42^{\circ}$, $34.59^{\circ}, 40.04^{\circ}, 42.64^{\circ}$, and $49.70^{\circ} 2 \theta$ correspond to the reflections (001), (011), (111), (002), (012), (112), (022), (003), and (222), respectively. ${ }^{46}$

Optical characterization of the perovskite single crystals was performed using a UV/vis/NIR Spectrometer Lambda 1050 equipped with a $150 \mathrm{~mm}$ InGaAs Int. Sphere (PerkinElmer). The UV/vis/NIR spectroscopy was applied in a transmission mode in order to estimate the onset of absorption. As expected, incorporation of iodide anions instead of bromide into the perovskite structure caused a shift of onsets of absorption closer to the NIR region. The transmission spectra in Figure 3A,B show clearly apparent onsets of absorption, which have been recalculated into an energy of 2.15, 2.12, 1.44, and $1.36 \mathrm{eV}$ for $\mathrm{MAPbBr}_{3}, \mathrm{FAPbBr}_{3}, \mathrm{MAPbI}_{3}$ and $\mathrm{FAPbI}_{3}$ crystals, respectively. The results are in agreement with the reported band gaps for the mentioned crystals, which are 2.28, $2.15,{ }^{47} 1.47,{ }^{48}$ and $1.41 \mathrm{eV},{ }^{44}$ respectively.

PL spectroscopy was performed on the perovskite crystals as well. PL spectra were recorded in a cryostat OptistatDry (Oxford Instruments), and a $405 \mathrm{~nm}$ laser for the excitation of the sample was used with a $420 \mathrm{~nm}$ LP filter. The emission maxima (see Figure 3C,D) of the recorded spectra were 546, 553, 782, and $829 \mathrm{~nm}$ for the $\mathrm{MAPbBr}_{3}, \mathrm{FAPbBr}_{3}, \mathrm{MAPbI}_{3}$, and $\mathrm{FAPbI}_{3}$ crystals, respectively. The excitation wavelength was set the same for all the measurement, $405 \mathrm{~nm}$, and the excitation power was $4 \mathrm{~mW}$. The previously reported values of emission maxima are 544, 587, 784, and $843 \mathrm{~nm}$, respectively. ${ }^{44}$ The shift of emission maxima as well as the broadening of the spectra can be attributed to the influence of autoabsorption ${ }^{49}$ and of crystal defects and surface states. ${ }^{47}$ Optical properties are summarized in Table 1.

Table 1. Optical Properties of Prepared Perovskite Crystals

\begin{tabular}{ccc} 
perovskite crystal & emission maximum $(\mathrm{nm})$ & onset of absorption $(\mathrm{eV})$ \\
$\mathrm{MAPbBr}_{3}$ & 546 & 2.15 \\
$\mathrm{FAPbBr}_{3}$ & 553 & 2.12 \\
$\mathrm{MAPbI}_{3}$ & 782 & 1.44 \\
$\mathrm{FAPbI}_{3}$ & 829 & 1.36 \\
\hline
\end{tabular}

In order to evaluate the difference between $\mathrm{MAPbBr}_{3}$ single crystals prepared by the microwave-assisted and by the conventional method described previously by our group, ${ }^{40-42}$ we compared the UV-vis and PL spectra of both crystals; see in Figure S2. As expected, the onset of absorption was identical for both samples; it was $2.15 \mathrm{eV}$. Interestingly, the shoulder in the higher wavelengths in emission spectrum did not appear in the case of the conventionally prepared crystal. The shoulder in the region of approximately $560 \mathrm{~nm}$ corresponds to the lowenergy transition state of the perovskite that is usually surpassed at room temperature. ${ }^{50}$ The reason that the shoulder is observed could be fewer amounts of defects in the crystal grown by the microwave-assisted method.

In conclusion, this communication presents a novel, costeffective microwave-assisted synthesis of perovskite single crystals. We have introduced a new method for preparation of $\mathrm{MAPbBr}_{3}, \mathrm{FAPbBr}_{3}, \mathrm{MAPbI}_{2}$, and $\mathrm{FAPbI}_{2}$ perovskite bulk crystals in a microwave reactor. The prepared perovskite crystals exhibit the same properties as when prepared by traditional ITC methods. This microwave-assisted method of perovskite crystallization is highly reproducible due to the precise heating control in the whole volume of the solution and the possibility of a fully automated program setting. This technique is convenient, versatile, and easily scalable, and it can be applied not only for the already mentioned types of perovskite materials, but also for various perovskite structure modifications. Moreover, our new method represents an environmentally friendly approach due to the very high energy efficiency and low energy consumption. We strongly believe that the microwave-assisted preparation of perovskite single crystals will make the fabrication of ultimate functional devices (such as solar cells, LEDs, photodetectors, etc.) more convenient and efficient.

\section{ASSOCIATED CONTENT}

\section{Supporting Information}

The Supporting Information is available free of charge at https://pubs.acs.org/doi/10.1021/acs.cgd.9b01670.

Detailed temperature program for perovskite single crystals preparation (Table S1), detailed power profile during the synthesis (Figure S1), and comparison of optical properties of crystals prepared by the microwaveassisted method and by the conventional ITC method (Figure S2) (PDF) 


\section{AUTHOR INFORMATION}

\section{Corresponding Author}

Jozef Krajcovic - Faculty of Chemistry, Materials Research Centre, Brno University of Technology, 61200 Brno, Czech Republic; Email: krajcovic@fch.vut.cz

\section{Authors}

Jan Jancik - Faculty of Chemistry, Materials Research Centre, Brno University of Technology, 61200 Brno, Czech Republic; (1) orcid.org/0000-0001-5346-6291

Anna Jancik Prochazkova - Faculty of Chemistry, Materials Research Centre, Brno University of Technology, 61200 Brno, Czech Republic; Institute of Physical Chemistry and Linz Institute of Organic Solar Cells, Johannes Kepler University Altenberger Straße, 694040 Linz, Austria

Markus Clark Scharber - Institute of Physical Chemistry and Linz Institute of Organic Solar Cells, Johannes Kepler University Altenberger Straße, 694040 Linz, Austria; ○ orcid.org/00000002-4918-4803

Alexander Kovalenko - Faculty of Chemistry, Materials Research Centre, Brno University of Technology, 61200 Brno, Czech Republic; 이이. orid.org/0000-0002-7194-1874

Jiŕí Másilko - Faculty of Chemistry, Materials Research Centre, Brno University of Technology, 61200 Brno, Czech Republic

Niyazi Serdar Sariciftci - Institute of Physical Chemistry and Linz Institute of Organic Solar Cells, Johannes Kepler University Altenberger Straße, 694040 Linz, Austria

Martin Weiter - Faculty of Chemistry, Materials Research Centre, Brno University of Technology, 61200 Brno, Czech Republic

Complete contact information is available at: https://pubs.acs.org/10.1021/acs.cgd.9b01670

\section{Author Contributions}

\#J.J. and A.J.P. contributed equally to this work.

\section{Notes}

The authors declare no competing financial interest.

\section{ACKNOWLEDGMENTS}

This work was supported by the Czech Science Foundation Grant No. 19-23718S. J.J. and A.J.P. acknowledge Project No. FCH-S-19-5834. The Austrian Science Foundation is gratefully acknowledged for the financial support within the Wittgenstein Prize for NSS (Z222-N19).

\section{REFERENCES}

(1) Liu, Y.; Yang, Z.; Cui, D.; Ren, X.; Sun, J.; Liu, X.; Zhang, J.; Wei, Q.; Fan, H.; Yu, F.; Zhang, X.; Zhao, C.; Liu, S. F. Two-InchSized Perovskite $\mathrm{CH}_{3} \mathrm{NH}_{3} \mathrm{PbX}_{3}(\mathrm{X}=\mathrm{Cl}, \mathrm{Br}, \mathrm{I})$ Crystals: Growth and Characterization. Adv. Mater. 2015, 27, 5176-5183.

(2) Stranks, S. D.; Eperon, G. E.; Grancini, G.; Menelaou, C.; Alcocer, M. J. P.; Leijtens, T.; Herz, L. M.; Petrozza, A.; Snaith, H. J. Electron-Hole Diffusion Lengths Exceeding 1 Micrometer in an Organometal Trihalide Perovskite Absorber: Growth and Characterization. Science 2013, 342, 341-344.

(3) Saidaminov, M. I.; Abdelhady, A. L.; Maculan, G.; Bakr, O. M. Retrograde solubility of formamidinium and methylammonium lead halide perovskites enabling rapid single crystal growth. Chem. Commun. 2015, 51, 17658-17661.

(4) Kim, Y. G.; Kwon, K. C.; Le, Q. V.; Hong, K.; Jang, H. W.; Kim, S. Y. Atomically thin two-dimensional materials as hole extraction layers in organolead halide perovskite photovoltaic cells. J. Power Sources 2016, 319, 1-8.
(5) Kim, Y. H.; Cho, H.; Heo, J. H.; Kim, T. S.; Myoung, N. S.; Lee, C. L.; Im, S. H.; Lee, T. W. Multicolored Organic/Inorganic Hybrid Perovskite Light-Emitting Diodes. Adv. Mater. 2015, 27, 1248-1254.

(6) Xing, G.; Mathews, N.; Lim, S. S.; Yantara, N.; Liu, X.; Sabba, D.; Gratzel, M.; Mhaisalkar, S.; Sum, T. C. Low-temperature solutionprocessed wavelength-tunable perovskites for lasing. Nat. Mater. 2014, $13,476-480$

(7) Fu, Y.; Zhu, H.; Schrader, A. W.; Liang, D.; Ding, Q.; Joshi, P.; Hwang, L.; Zhu, X. Y.; Jin, S. Nanowire Lasers of Formamidinium Lead Halide Perovskites and Their Stabilized Alloys with Improved Stability. Nano Lett. 2016, 16, 1000-1008.

(8) Liu, P.; He, X.; Ren, J.; Liao, Q.; Yao, J.; Fu, H. OrganicInorganic Hybrid Perovskite Nanowire Laser Arrays. ACS Nano 2017, 11, 5766-5773.

(9) Dong, R.; Fang, Y.; Chae, J.; Dai, J.; Xiao, Z.; Dong, Q.; Yuan, Y.; Centrone, A.; Zeng, X. C.; Huang, J. High-Gain and Low-DrivingVoltage Photodetectors Based on Organolead Triiodide Perovskites. Adv. Mater. 2015, 27, 1912-1918.

(10) Fang, Y.; Huang, Y. J. Resolving Weak Light of Sub-picowatt per Square Centimeter by Hybrid Perovskite Photodetectors Enabled by Noise Reduction. Adv. Mater. 2015, 27, 2804-2810.

(11) Kwon, K. C.; Hong, K.; Van Le, Q.; Lee, S. Y.; Choi, J.; Kim, K.-B.; Kim, S. Y.; Jang, H. W. Inhibition of Ion Migration for Reliable Operation of Organolead Halide Perovskite-Based Metal/Semiconductor/Metal Broadband Photodetectors. Adv. Funct. Mater. 2016, 26, 4213-4222.

(12) Yakunin, S.; Sytnyk, M.; Kriegner, D.; Shrestha, S.; Richter, M.; Matt, G. J.; Azimi, H.; Brabec, C. J.; Stangl, J.; Kovalenko, M. V.; Heiss, W. Detection of X-ray photons by solution-processed lead halide perovskites. Nat. Photonics 2015, 9, 444-449.

(13) Yakunin, S.; Dirin, D. N.; Shynkarenko, Y.; Morad, V.; Cherniukh, I.; Nazarenko, O.; Kreil, D.; Nauser, T.; Kovalenko, M. Detection of gamma photons using solution-grown single crystals of hybrid lead halide perovskites. Nat. Photonics 2016, 10, 585-589.

(14) Tang, Z.; Xu, Z.; Zhang, D.; Hu, S.; Lau, W.; Liu, L. Enhanced optical absorption via cation doping hybrid lead iodine perovskites. Sci. Rep. 2017, 7, 7843.

(15) Saidaminov, M. I.; Abdelhady, A.; Murali, B.; et al. High-quality bulk hybrid perovskite single crystals within minutes by inverse temperature crystallization. Nat. Commun. 2015, 6, 7586.

(16) Babu, R.; Giribabu, L.; Singh, S. Recent Advances in HalideBased Perovskite Crystals and Their Optoelectronic Applications. Cryst. Growth Des. 2018, 18, 2645-2664.

(17) Hong, K.; Le, Q. V.; Kim, S. Y.; Jang, H. W. Low-dimensional halide perovskites: review and issues. J. Mater. Chem. C 2018, 6, 2189-2209.

(18) Chen, L.; Tan, Y.; Chen, Z. X.; Wang, T.; Hu, S.; Nan, Z. A.; Xie, L. Q.; Hui, Y.; Huang, J. X.; Zhan, Ch.; Wang, S. H.; Zhou, J. Z.; Yan, J. W.; Mao, B. W.; Tian, Z. Q. Toward Long-Term Stability: Single-Crystal Alloys of Cesium-Containing Mixed Cation and Mixed Halide Perovskite. J. Am. Chem. Soc. 2019, 141, 1665-1671.

(19) Ball, J. M.; Lee, M.; Hey, A.; Snaith, H. J. Low-temperature processed meso-superstructured to thin-film perovskite solar cells. Energy Environ. Sci. 2013, 6, 1739-1743.

(20) Zhao, Y.; Zhu, K. $\mathrm{CH}_{3} \mathrm{NH}_{3} \mathrm{Cl}$-Assisted One-Step Solution Growth of $\mathrm{CH}_{3} \mathrm{NH}_{3} \mathrm{PbI}_{3}$ : Structure, Charge-Carrier Dynamics, and Photovoltaic Properties of Perovskite Solar Cells. J. Phys. Chem. C 2014, 118, 9412-9418.

(21) Ahn, N.; Son, D. Y.; Jang, I. H.; Kang, S. M.; Choi, M.; Park, N. G. Highly Reproducible Perovskite Solar Cells with Average Efficiency of $18.3 \%$ and Best Efficiency of $19.7 \%$ Fabricated via Lewis Base Adduct of Lead(II) Iodide: Structure, Charge-Carrier Dynamics, and Photovoltaic Properties of Perovskite Solar Cells. J. Am. Chem. Soc. 2015, 137, 8696-8699.

(22) Hailegnaw, B.; Adam, G.; Wielend, D.; Pedarnig, J. D.; Sariciftci, N. S.; Scharber, M. C. Acetylacetone Improves the Performance of Mixed Halide Perovskite Solar Cells. J. Phys. Chem. C 2019, 123, 23807-23816. 
(23) Hailegnaw, B.; Poscher, V.; Ulbricht, Ch.; Seelajaroen, H.; Teasdale, I.; Salinas, Y.; Sariciftci, N. S.; Scharber, M. C. Improving the Performance of Perovskite Solar Cells using a Polyphosphazene Interfacing Layer. Phys. Status Solidi A 2019, 216, 1900436.

(24) Hailegnaw, B.; Paek, S.; Cho, K. T.; Lee, Y.; Ongul, F.; Nazeeruddin, M.; Scharber, M. C. Optoelectronic Properties of Layered Perovskite Solar Cells. Solar RRL. 2019, 3, 1900126.

(25) Elumalai, N. K.; Uddin, A. Hysteresis in organic-inorganic hybrid perovskite solar cells. Sol. Energy Mater. Sol. Cells 2016, 157, 476-509.

(26) Chen, B.; Yang, M.; Priya, S.; Zhu, K. Origin of J-V Hysteresis in Perovskite Solar Cells. J. Phys. Chem. Lett. 2016, 7, 905-917.

(27) Xu, F.; Zhang, T.; Li, G.; Zhao, Y. Mixed cation hybrid lead halide perovskites with enhanced performance and stability. J. Mater. Chem. A 2017, 5, 11450-11461.

(28) Tenuta, E.; Zheng, C.; Rubel, O. Thermodynamic origin of instability in hybrid halide perovskites. Sci. Rep. 2016, 6, 37654.

(29) Daub, M.; Hillebrecht, H. Synthesis, Single-Crystal Structure and Characterization of $\left(\mathrm{CH}_{3} \mathrm{NH}_{3}\right)_{2} \mathrm{~Pb}(\mathrm{SCN})_{2} \mathrm{I}_{2}$. Angew. Chem., Int. Ed. 2015, 54, 11016-11017.

(30) Dang, Y.; Liu, Y.; Sun, Y.; Yuan, D.; Liu, X.; Lu, W.; Liu, G.; Xia, H.; Tao, X. Bulk Crystal Growth of Hybrid Perovskite Material $\mathrm{CH}_{3} \mathrm{NH}_{3} \mathrm{PbI}_{3}$. CrystEngComm 2015, 17, 665-670.

(31) Liu, Y.; Sun, J.; Yang, Z.; Yang, D.; Ren, X.; Xu, H.; Yang, Z.; Liu, S. 20-mm-Large Single-Crystalline Formamidinium-Perovskite Wafer for Mass Production of Integrated Photodetectors. Adv. Opt. Mater. 2016, 4, 1829-1837.

(32) Shi, D.; Adinolfi, V.; Comin, R.; Yuan, M.; Alarousu, E.; Buin, A.; Chen, Y.; Hoogland, S.; Rothenberger, A.; Katsiev, K.; Losovyj, Y.; Zhang, X.; Dowben, P. A.; Mohammed, O. F.; Sargent, E. H.; Bakr, O. M. Low Trap-State Density and Long Carrier Diffusion in Organolead Trihalide Perovskite Single Crystals. Science 2015, 347, 519.

(33) Dang, Y.; Zhou, Y.; Liu, X.; Ju, D.; Xia, S.; Xia, H.; Tao, X. Formation of Hybrid Perovskite Tin Iodide Single Crystals by Top Seeded Solution Growth. Angew. Chem., Int. Ed. 2016, 55, 34473450.

(34) Lian, Z.; Yan, Q.; Gao, T.; Ding, J.; Lv, Q.; Ning, C.; Li, Q.; Sun, J. Deciphering Halogen Competition in Organometallic Halide Perovskite Growth. J. Am. Chem. Soc. 2016, 138, 9409-5035.

(35) Takahashi, Y.; Obara, R.; Lin, Z. - Z.; Takahashi, Y.; Naito, T.; Inabe, T.; Ishibashi, S.; Terakura, K. Charge-Transport in Tin-Iodide Perovskite $\mathrm{CH}_{3} \mathrm{NH}_{3} \mathrm{SnI}_{3}$ : Origin of High Conductivity. Dalton Trans. 2011, 40, 5563-5568.

(36) Stoumpos, C. C.; Malliakas, C. D.; Peters, J. A.; Liu, Z.; Sebastian, M.; Im, J.; Chasapis, T. C.; Wibowo, A. C.; Chung, D. Y.; Freeman, A. J.; Wessels, B. W.; Kanatzidis, M. G. Crystal Growth ofthe Perovskite Semiconductor $\mathrm{CsPbBr}_{3}$ : A New Material for High Energy Radiation Detection. Cryst. Growth Des. 2013, 13, 2722-2727.

(37) Yu, Y.-Y.; Chen, P.-K. Nanocomposites of polymer and inorganic nanoparticles prepared by focused microwave polymerization for optical thin films applications. Thin Solid Films 2013, 544, $48-54$.

(38) Xu, G.; Zhang, Y.; Wang, K.; Fu, Y.; Du, Z. Microwave-assisted Stille cross-coupling reaction catalysed by in situ formed palladium nanoparticles. J. Chem. Res. 2015, 39, 399-402.

(39) Microwaves in Organic and Medicinal Chemistry. In Methods and Principles in Medicinal Chemistry; Weinheim, FRG, 2005.

(40) Kovalenko, A.; Pospíšil, J.; Zmeškal, O.; Krajčovič, J.; Weiter, $\mathrm{M}$. Ionic origin of a negative capacitance in lead halide perovskites. Phys. Status Solidi RRL 2017, 11, 1600418.

(41) Kovalenko, A.; Pospisil, J.; Krajcovic, J.; Weiter, M.; Guerrero, A.; Garcia-Belmonte, G. Interface inductive currents and carrier injection in hybrid perovskite single crystals. Appl. Phys. Lett. 2017, 111, 163504.

(42) Pospíšil, J.; Zmeškal, O.; Nešpurek, S.; Krajčovič, J.; Weiter, M.; Kovalenko, A. Density of bulk trap states of hybrid lead halide perovskite single crystals: temperature modulated space-chargelimited-currents. Sci. Rep. 2019, 9, 1-8.
(43) Wang, K. H.; Li, L. C.; Shellaiah, M.; Sun, W. K. Structural and Photophysical Properties of Methylammonium Lead Tribromide $\left(\mathrm{MAPbBr}_{3}\right)$ Single Crystals. Sci. Rep. 2017, 7, 13643.

(44) Zhumekenov, A. A.; Saisaminov, M. I.; Haque, M. A.; et al. Formamidinium Lead Halide Perovskite Crystals with Unprecedented Long Carrier Dynamics and Diffusion Length. ACS Energy Lett. 2016, $1,32-37$.

(45) Oku, T. Crystal Structures of $\mathrm{CH}_{3} \mathrm{NH}_{3} \mathrm{PbI}_{3}$ and Related Perovskite Compounds Used for Solar Cells. In Solar Cells - New Approaches and Reviews; InTech, 2015; pp 10-22.

(46) Weller, M. T.; Weber, O. J.; Frost, M. J.; Walsh, A. Cubic Perovskite Structure of Black Formamidinium Lead Iodide, $\alpha$ $\left[\mathrm{HC}\left(\mathrm{NH}_{2}\right)_{2}\right] \mathrm{PbI}_{3}$, at $298 \mathrm{~K}$. J. Phys. Chem. Lett. 2015, 6, 3209-3212.

(47) Wang, L.; Yuan, G. D.; Duan, R. F.; Huang, F.; Wei, T. B.; Liu, Q. Z.; Wang, J. X.; Li, J. M. Tunable bandgap in hybrid perovskite $\mathrm{CH}_{3} \mathrm{NH}_{3} \mathrm{~Pb}\left(\mathrm{Br}_{3}-\mathrm{yXy}\right)$ single crystals and photodetector applications. AIP Adv. 2016, 6, 045115 .

(48) Huang, W.; Liu, Y.; Yue, S.; Zhu, L.; Jin, P.; Wu, Q.; Zhang, Y.; $\mathrm{Qu}, \mathrm{S}$.; Wang, Z.; Chen, Y. Optical bandgap energy of $\mathrm{CH}_{3} \mathrm{NH}_{3} \mathrm{PbI}_{3}$ perovskite studied by photoconductivity and reflectance spectroscopy. Sci. China: Technol. Sci. 2018, 61, 886-892.

(49) Wenger, B.; Nayak, P. K.; Wen, X.; Kesava, S.; Noel, K. N.; Snaith, H. J. Consolidation of the optoelectronic properties of $\mathrm{CH}_{3} \mathrm{NH}_{3} \mathrm{PbBr}_{3}$ perovskite single crystals. Nat. Commun. 2017, 8, 590 .

(50) Chen, Y.; Wang, T.; Li, Z.; Li, H.; Ye, T.; Wetzel, C.; Li, H.; Shi, S.-F. Communicating Two States in Perovskite Revealed by Time-Resolved Photoluminescence Spectroscopy. Sci. Rep. 2018, 8, 16482. 